\title{
Surgical approximation of the posterior papillary muscle in chronic ischemic mitral regurgitation - presentation of a new method of mitral valve repair
}

\author{
N Alotti ${ }^{*}$, K Gombocz $^{1}$, A Rashed ${ }^{1}$, Cs Dézsi $^{2}$, A Sayur $^{2}$ \\ From 23rd World Congress of the World Society of Cardio-Thoracic Surgeons \\ Split, Croatia. 12-15 September 2013
}

\section{Background}

The optimal surgical management of the chronic ischemic mitral regurgitation remains controversial and the negative effect of the displacement of the papillary muscles is evident. To emerge this effect we performed a new method to approximate the papillary muscles as adjunct procedure to ring annuloplasty. The purpose of this study was to evaluate the early outcome and the effect of this method.

\section{Methods}

Between 2007 and 2012108 patients (mean age 63.8 years; range: $48-78$ years) with a preoperative diagnosis of functional MR underwent either annuloplasty \pm new chordal implantation (group $\mathrm{AC}, \mathrm{N}=56$ ) or annuloplasty + papillary muscle approximation + new chordal implantation (group AAC, $\mathrm{N}=52$ ) for mitral valve repair along with myocardial revascularization (1.9 \pm 1.0 distal anastomoses per patients). A Carpentier ring was always used in the repair procedures. Papillary muscle approximation was achieved with auto-pericardium pledgeted U shaped, Bridge like polytetrafluoroethylene suture placed between the head of the two papillary muscles, creating a distance $\leq 15 \mathrm{~mm}$. We compared echocardiographic and clinical data for these two groups. The two groups were homogeneous for preoperative characteristics.

\section{Results}

Follow-up was $98.2 \%$ and $100 \%$ complete in the $\mathrm{AC}$ and AAC groups, respectively. No operative mortality was observed. At 5 years, overall survival was 89,3 in the AC group, and $94,2 \%$ in the AAC group $(\mathrm{P}=.05)$ No reoperation was required. 6 months after the operation 91 patients showed no leakage, 9 had trivial regurgitation and 8 had regurgitation grade $\geq 1(44,5,7$ in AC group, 47, 4, 1 in AAC group respectively) New York Heart Association functional class I or II was documented in 92.3\% of patients in the AC group and $95.9 \%$ in the AAC group $(\mathrm{P}=.1)$.

\section{Conclusions}

Papillary muscle approximation as adjunct procedure to annuloplasty in functional MR was valuable for eliminating MR. However, this technique may influence long term outcome and survival.

\section{Authors' details}

${ }^{1}$ Cardiac Surgery Department of Zala County Hospital \& Pécs University, Zalaegerszeg, Hungary. ${ }^{2}$ Cardiology Department of Petz Aladár Hospital, Győr, Hungary.

Published: 11 September 2013

\section{doi:10.1186/1749-8090-8-S1-O268}

Cite this article as: Alotti et al:: Surgical approximation of the posterior papillary muscle in chronic ischemic mitral regurgitation - presentation of a new method of mitral valve repair. Journal of Cardiothoracic Surgery 2013 8(Suppl 1):O268.

\footnotetext{
* Correspondence: nalotti@hotmail.com

'Cardiac Surgery Department of Zala County Hospital \& Pécs University,

Zalaegerszeg, Hungary

Full list of author information is available at the end of the article
}

(c) 2013 Alotti et al; licensee BioMed Central Ltd. This is an Open Access article distributed under the terms of the Creative Commons Attribution License (http://creativecommons.org/licenses/by/2.0), which permits unrestricted use, distribution, and reproduction in any medium, provided the original work is properly cited. 